\title{
Structural Health Monitoring for Concrete Structure using Impedance Chip
}

\author{
T. Jayachitra, Rashmi Priyadarshini
}

\begin{abstract}
Structural Health monitoring plays a vital role in all generations for the safety of life and property. The method of Electromechanical Impedance (EMI) method and sensors are used in damage detection of civil and mechanical structures. The structure deteriorates due to ageing and environmental factors. This study represents the detection of damage in concrete structure using piezo electric transducer and EMI method. The piezo sensor is bonded to the concrete structure using epoxy resin and damage is created by using flexural testing machine. The force is applied using flexural testing machine at different KiloNewton. The output from the impedance chip is noted at undamaged state and at all levels of applied force. The impedance, admittance, conductance and susceptance curves are drawn with different levels of frequency. Root mean square deviation is also calculated for the detection of damage. The results conclude that Impedance chip is highly reliable and accurate in damage detection of concrete structure.
\end{abstract}

Keywords: Structural Health Monitoring; Electromechanical Impedance method; Impedance chip; Root mean square deviation; piezo sensors

\section{INTRODUCTION}

Civil and Mechanical structures starts degrading after years due to environmental factors and loading effects. Therefore monitoring of these structures is required at regular intervals of time to avoid damage to life and property. Structural Health Monitoring monitors the structure at all times to identify the existing damage, location and severity of damage[1].In order to reduce the maintenance and repairing cost ,Non Destructive Evaluation(NDE) technique is preferred. The most encouraging NDE is Electromechanical Impedance Technique (EMI).EMI technique works on piezoelectric property principle. When piezoelectric transducer is bonded or embedded in the civil or mechanical structure which is excited at suitable frequency range, any change in mechanical impedance of the structure is measured

Revised Manuscript Received on February 05, 2020.

* Correspondence Author

T. Jayachitra *, Electrical and Electronics Engineering Department, School of Engineering \& Technology, Sharda University, Greater Noida, Uttar Pradesh 201310, India.Email: jayachitra.kishor@sharda.ac.in

Rashmi Priyadarshini, Electronics and Communication Department, School of Engineering \& Technology, Sharda University, Greater Noida, Uttar Pradesh 201310, India.Email: rashmi.priyadarshini@sharda.ac.in

(c) The Authors. Published by Blue Eyes Intelligence Engineering and Sciences Publication (BEIESP). This is an open access article under the CC BY-NC-ND license (http://creativecommons.org/licenses/by-nc-nd/4.0/) as electrical impedance of the piezoelectric transducer [2].EMI technique was first proposed by Liang et al. The result of Impedance method was compared with static and dynamic finite element approaches [3].

Different structures are chosen for experimentation of damage using EMI Technique. Structures like aluminium beam, concrete, steel etc were used [4].Fabricio Guimarães Baptista et al evaluated the impedance measurement system on Aluminium structure and proved that the excitation signal influence the output impedance measurement[5] Impedance Analyzers or LCR meter are used for measuring impedance. The cost of these components is high and the size is also bulk. Therefore, in order to minimize the cost and size, Impedance chip was used [6].The Piezo sensors are embedded in different orientations and hydration of Reinforced concrete beam was monitored [7].Naveet et al made a comparison study on bonded, embedded and metal wire transducer[8]

Piezo sensor and Impedance chip are used for detecting the damage in structures. Impedance (AD5933) is a precise Impedance converter which has frequency generator, analog to digital converter, DSP engine and temperature sensor. Excitation is provided by the frequency generator and processed by DSP engine. The real and imaginary data is obtained at each sweep frequency .The clock frequency of the impedance chip is $16 \mathrm{MHz}$. The user defined software requires calibration at every time when it is restarted.200 Kilo ohm resistance is added for circuit calibrations[9].The only drawback in using impedance chip is repeatability. The output is repeatedly measured to measure the impedance. Using Impedance chip, damage was detected on bolted joint structure used for railway joints[10].

\section{METHODOLOGY}

Concrete beam structure of size $500 \times 100 \times 100 \mathrm{~mm}$ is chosen for experimentation. Damage is induced in the structure by using flexural testing machine. Piezo electric transducer of Lead zirconate titanate patches are bonded in the structure and output is measured at full strength of the concrete beam. Then damage is created by applying the force using Flexural testing machine at different level in the concrete structure and the corresponding output is measured from Impedance chip. The concrete is placed in flexural testing machine and force is applied at $5 \mathrm{KN}$ and output is measured. Then the same process is repeated at $9 \mathrm{KN}, 12 \mathrm{KN}$ and $16 \mathrm{KN}$.The concrete structure is fully damaged after the level of $20 \mathrm{KN}$.Fig1 shows the Impedance chip and user define software of AD5933.Fig 2. shows the setup of concrete beam and Impedance chip. The damage is detected by measuring the Impedance, admittance, susceptance with frequency. The results are shown in section III. 


\section{Structural Health Monitoring for Concrete Structure using Impedance Chip}
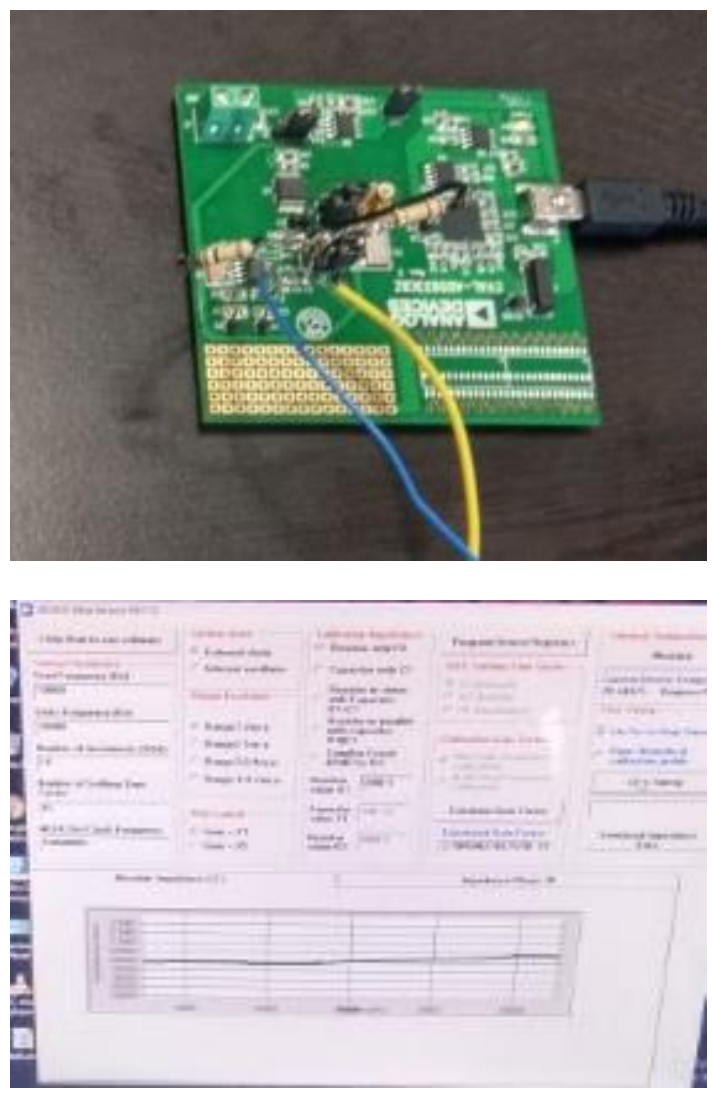

Fig. 1. Impedance chip and User Defined software of AD5933

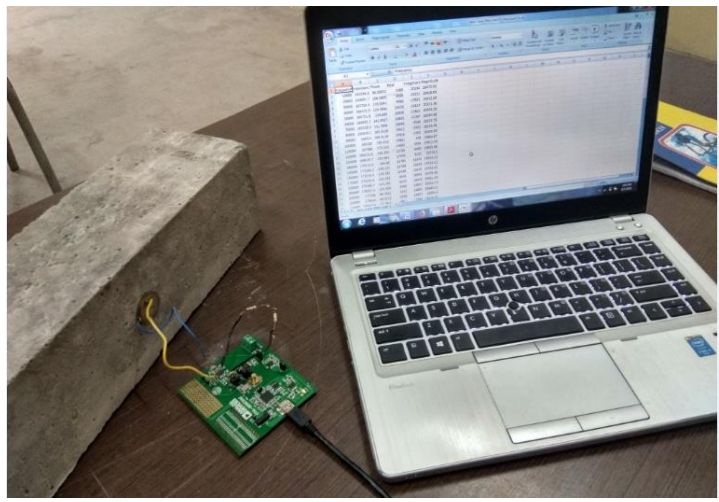

Fig. 2. Experimental setup of concrete structure

\section{RESULTS}

The impedance is measured at the undamaged level and considered as base signature. Then the force is applied on the concrete using flexural machine at $5 \mathrm{KN}, 9 \mathrm{KN}, 12 \mathrm{KN}$ and
$16 \mathrm{KN}$ and the corresponding output from the Impedance chip is measured. Fig 3 to Fig 6 represents the impedance, admittance, conductance, susceptance versus frequency. The damage state is identified by peaks when compared with the undamaged state. The result indicates that the impedance increases as the level of damage increases. Root mean square deviation (RMSD) is calculated by

RMSD $\%=\sqrt{\frac{\sum_{i=1}^{M L}\left(y_{i}-X_{i}\right)^{2}}{\sum_{i=1}^{m} x_{i}^{2}}}$

Where $X_{\mathrm{i}}$ represents the baseline conductance signature for $\mathrm{i}=1,2 \ldots \ldots \mathrm{n}$, where $\mathrm{n}$ is the number of observation and $Y_{\tilde{i}}$ represents the conductance signatures due to damage. Fig 7 represents RMSD indices comparison between undamaged state and damaged state. The RMSD is less in $5 \mathrm{KN}$ and it increases at $12 \mathrm{KN}$ and this indicates that the damage is detected when the applied force is more than lesser one. Then at further increase in the application of force the RMSD is reduced. The damage in the concrete is detected at $5 \mathrm{KN}$.Table-I show the various parameters like impedance, admittance, conductance and susceptance at undamaged state and different levels of damaged state.

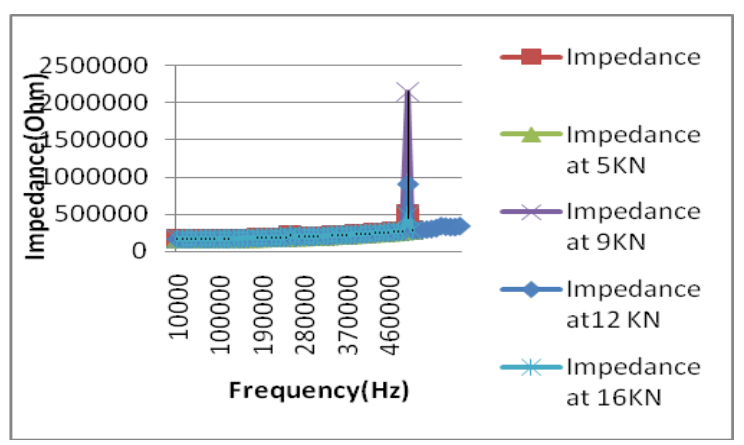

Fig. 3. Impedance signature at different frequency range

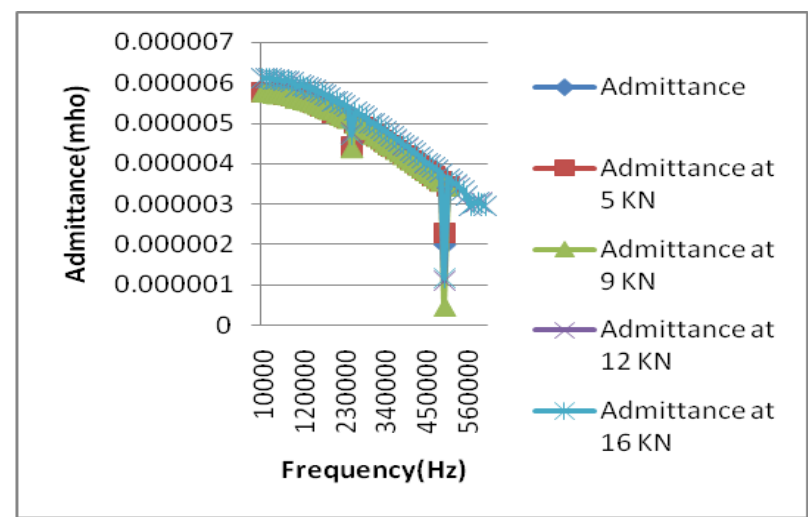

Fig. 4. Admittance signature at different frequency range

Table- I: Results of various parameters with respect to different damage state

\begin{tabular}{|l|l|l|l|l|l|}
\hline Parameters & $\begin{array}{l}\text { Undamaged } \\
\text { state }\end{array}$ & Force at 5KN & Force at 9KN & Force at 12KN & Force at 16KN \\
\hline Impedance(ohm) & $5.05 \mathrm{E}+05$ & $4.42 \mathrm{E}+05$ & $2.15 \mathrm{E}+06$ & $9.04 \mathrm{E}+05$ & $4.89 \mathrm{E}+05$ \\
\hline Admittance(mho) & $1.97 \mathrm{E}-06$ & $2.26 \mathrm{E}-06$ & $4.64 \mathrm{E}-07$ & $1.11 \mathrm{E}-06$ & $1.15 \mathrm{E}-06$ \\
\hline Conductance(mho) & 0.0019 & 0.00084 & 0.0012 & 0.0017 & 0.00199 \\
\hline
\end{tabular}


$\mathbf{0 . 0 0 0 9 7}$

0.00278

0.0011

2. Cortez E Nicola's, Filho Vieira Jozue and Baptista G Fabricio "A new microcontrolled structural health monitoring system based on the electromechanical impedance principle.",Structural Health Monitoring Vol.12,No.1,2012,pp 14-22.

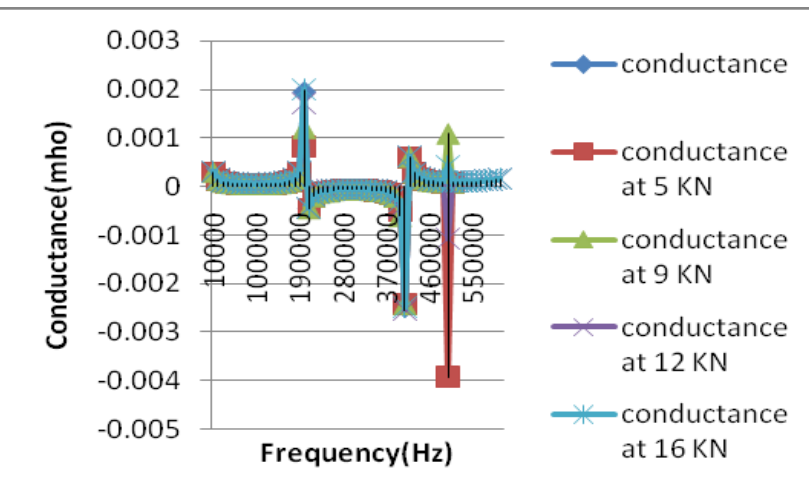

Fig. 5. Conductance signature at different frequency range

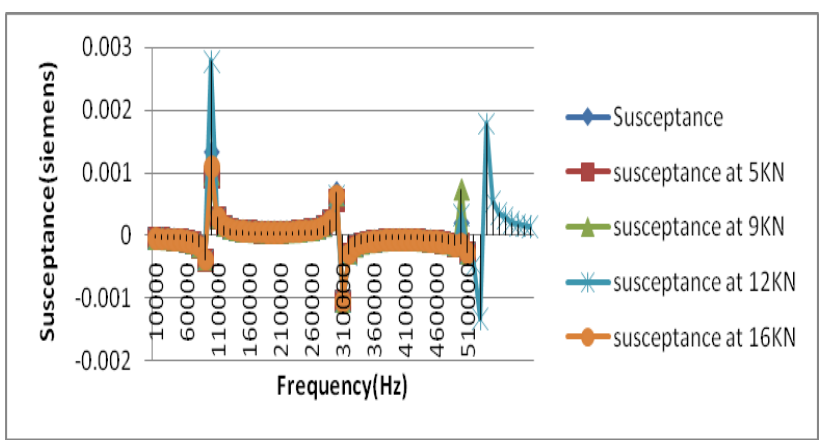

Fig. 6. Susceptance signature at different frequency range

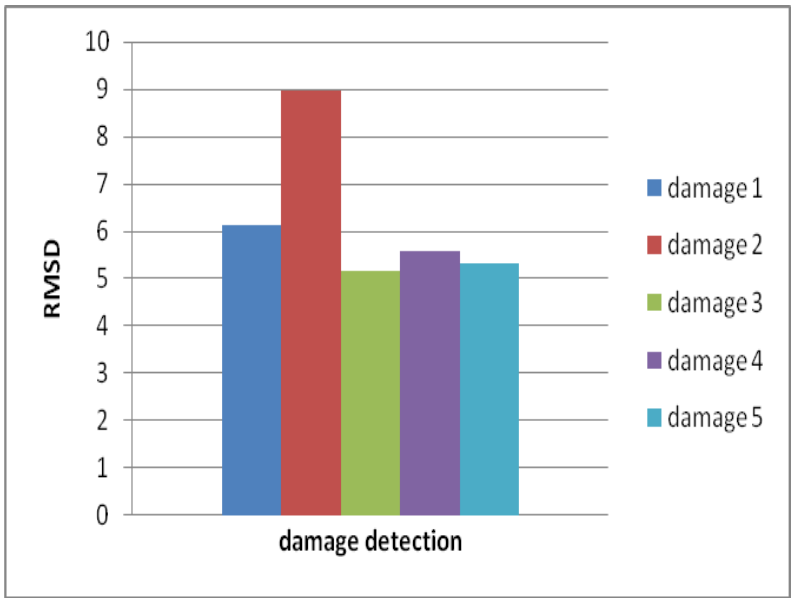

Fig. 7. RMSD comparison between undamaged and damaged structure

\section{CONCLUSION}

The objective of this paper to check the strength of concrete using low cost Impedance chip. In this evaluation, Impedance chip is used to detect the damage in concrete structure. The result identifies that the Impedance chip is highly reliable and accurate in detecting the damages in the structure but repeatability process is required in the output measurement.

\section{REFERENCES}

1. Rama Shanker "An Integrated Approach for Structural health Monitoring”, Thesis Indian Institute of Technology, Delhi, 2009.
3. Liang C, Sun FP, Rogers CA. "An impedance method for dynamic analysis of active material system" Trans ASME, J Vib Acoust 1994;116:120-8.

4. Annamdas GM. Venu and Radhika A. Madhav, "Electromechanical Impedance of Piezoelectric transducers for monitoring metallic and non metallic structures: A review of wired, wireless and energy -harvesting methods," Journal of Intelligent Material Systems and Structures, Vol 24, No.9,2013, pp 1021-1042.

5. Baptista Guimara Fabricio.,Filho Vieria Jozue and Inman J Daniel, "Influence of Excitation Signal on Impedance-based Structural Health Monitoring, " Journal of Intelligent Material Systems and structures Vol. 21,2010,pp 1409-1416.

6. Naveet Kaur, Lingfang Li, Suresh Bhalla and Yong Xia, "A low-cost version of electro-mechanical impedance technique for damage detection in reinforced concrete structures using multiple piezo configurations," Advances in Structural Engineering, Vol. 20(8),2017, pp 1247-1254.

7. P. Negi, T. Chakraborty, Naveet Kaur, Suresh Bhalla, "Investigation of effectiveness of embedded PZT patches at varying orientations for monitoring concrete hydration using EMI technique," Construction and Building Materials ( 169), 2018,pp 489-98.

8. Naveet Kaur, Lingfang Li, Suresh Bhalla, Yong Xia, PingheNi and Sailesh Adhikari " Integration and evaluation of multiple piezo configurations for optimal health monitoring of reinforced concrete structures," Journal of Intelligent Material Systems and Structures, Vol. 28(19) ,2017,2717-2736.

9. Devices A (1 April) 1 MSPS, 12 Bit Impedance converter Network Analyzer. Available: http://www.analog.com/en/index.html.

10. Samantaray S.K, Mittal S.K, Mahapatra P, Kumar S " An impedance-based structural health monitoring approach for looseness identification in bolted joint structure," Journal of Civil Structural Health Monitoring 8,2018,pp 809-822.

\section{AUTHORS PROFILE}

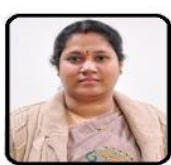

t.jayachitra, is currently pursuing her $\mathrm{PhD}$ in Department of Electrical and Electronics Engineering, Sharda University, Greater Noida, Uttar Pradesh, India. Her research interests are Wireless Sensor Network, Microstrip antennas and IoT.

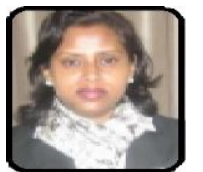

Rashmi Priyadarshini, is an Associate Professor in Department of Electronics and Communication, Sharda University, Greater Noida, Uttar Pradesh, India. She completed her PhD degree from Sharda University. Her research interests are Wireless Sensor Network, Embedded systems and IoT. She has published many papers in reputed Journals and Conferences. 